\title{
Student Engagement Through Creation of New Activities: An Empirical Study on Contributing Student Pedagogy
}

\author{
Mirna Carelli O. Maia ${ }^{1}$, Eliane Cristina de Araújo ${ }^{2}$, \\ Jorge C. A. de Figueiredo ${ }^{2}$, Dalton Dario Serey Guerrero ${ }^{2}$ \\ ${ }^{1}$ Instituto Federal de Educação, Ciência e Tecnologia da Paraíba (IFPB) \\ Campina Grande - Paraíba - Brazil \\ ${ }^{2}$ Universidade Federal de Campina Grande (UFCG) \\ Campina Grande - Paraíba - Brazil \\ mirna.maia@ifpb.edu.br \\ (eliane, abrantes, dalton) @computacao.ufcg.edu.br
}

\begin{abstract}
Contributing Student Pedagogy is an active methodology that encourages students to contribute to community learning and value the contribution of others. In this way, students are guided to produce study material, develop new exercises, and to discuss and evaluate the work of others. This article presents an experimental study to assess how the creation of new exercises influences student engagement in programming learning activities. The results suggest that this activity affects emotional and cognitive but not behavioral engagements. Contributing students developed more difficult programs to solve. From an emotional point of view, they felt more stimulated, satisfied, productive, and happy.
\end{abstract}

\begin{abstract}
Resumo. A Pedagogia do Aluno Contribuinte é uma metodologia ativa que incentiva os alunos a contribuir para a aprendizagem da comunidade e a valorizar a contribuição dos outros. Desta forma, os alunos são orientados a produzir material de estudo, desenvolver novos exercícios, discutir e avaliar o trabalho de outras pessoas. Este artigo apresenta um estudo experimental para avaliar como a criação de novos exercícios afeta o envolvimento do aluno em atividades de aprendizagem de programação. Os resultados sugerem que esta atividade afeta o envolvimento emocional e cognitivo, mas não o comportamento. Os contribuintes desenvolveram programas mais difíceis de resolver. No ponto de vista emocional, se sentiram mais estimulados, satisfeitos, produtivos e felizes.
\end{abstract}

\section{Introduction}

There is an abundance of literature discussing and proposing pedagogical interventions to mitigate the challenges of programming education [Pears 2010, Eltegani and Butgereit 2015, Luxton-Reilly et al. 2018]. The last decade witnessed an increased interest in research related to student engagement characterizing it as an essential factor in coping with those issues and supporting learning [Lester 2013, Maia et al. 2019].

Student engagement involves behavioral, cognitive, and emotional dimensions. Students who are behaviourally engaged comply with class attendance and do not present disruptive or harmful behavior. Cognitively engaged students go beyond expectations 
and challenge themselves to learn continually. Those who are emotionally involved can experience positive affective reactions such as interest or enjoyment [Sinatra et al. 2015].

Active methodologies place the students at the center of the learning process and make them the protagonists of discovery, rather than just passive information receivers [Konopka et al. 2015]. Contributing Student Pedagogy (CSP) is an active learning method that encourages students to contribute to community learning and value the contributions of others. Activities based on contribution can guide students to produce study material for community usage and discuss and evaluate the contribution of others [Hamer et al. 2012]. The development of new programming exercises is an example of CSP-based activity, and it can influence student performance in examinations [Falkner and Falkner 2012, Kay 2016]. However, we know very little about the relationship between the emotional aspects of student engagement and the development of new programming activities. In general, literature in programming education shows few advances in strategies to explore affective and emotional factors [Luxton-Reilly et al. 2018].

This article presents a study investigating how the development of new programming activities to community affects the three dimensions of student engagement in an introductory programming course. To achieve this goal, we conducted an experimental study to answer the research question What are the effects on the dimensions of engagement of those who develop new programming activities? We use indicators to evaluate behavioral and cognitive dimensions of engagement of students, and we applied a posttest survey to subjects to report the emotional states experienced.

The results suggest that the development of new programming exercises can affect cognitive and emotional engagement, without affecting the behavioral dimension. The contribution can improve the experience of affective states of feeling more included, influential, stimulated, productive, satisfied, productive, and happy. While it can decrease the state of feeling relevant, powerful, proud, careful, ashamed and astonished.

\section{Background}

This section defines student engagement and its dimensions, while also discusses the contributing student pedagogy that constitutes the theoretical framework on which this study is based.

\subsection{Student Engagement}

Student engagement is a multifaceted concept that includes not only the involvement and participation of the subject but also their feelings and a sense of belonging [Lester 2013]. Researchers have identified at least three dimensions to student engagement [Sinatra et al. 2015].

Behavioural engagement refers to the students' comply with norms, participation, and involvement in school activities, academic, social or extracurricular [Fredricks et al. 2004]. Cognitive engagement includes the amount of effort invested in the learning task, specifically when students are engaged in thinking and learning [Sesmiyanti 2016]. And Emotional engagement refers to affective reactions and students' sense of belonging to the school. It is comprised of students' responses to interactions with faculty, staff, students, academics, or the institution. It has three components: students' affective reactions, emotional reactions, and school identification. Affective reac- 
tions include reactions like student interests, anxiety, sadness, and happiness. Emotional reactions are feelings toward the institution and instructors. School identification pertains to students' perceptions of belonging [Lee 2012, Lester 2013].

Using the concepts mentioned above, we adapted the definition of student engagement to Programming Education as been:

All features that influence the programming learning experience, including attitudes of students both inside and outside of the classroom, their cognitive efforts and emotions while studying programming.

\subsection{Contributing Student Pedagogy}

Contributing Student Pedagogy (CSP) is an approach that emphasizes activities involving students as an active contributor to the experiences and learning resources of himself and others [Collis and Moonen 2006]. Its definition considers the student's perspective as who contributes and who uses the contribution of other individuals [Hamer et al. 2012]:

"A pedagogy that encourages students to contribute to community learning and to value the contributions of others."

CSP includes activities for sharing solutions, creating study material, and reviewing the work of others. The development of these activities offers opportunities for students to experience important skills such as critical thinking, creativity, and improving interpersonal relationships [Falkner and Falkner 2012]. We detail these activities as follows:

- Development of questions and solutions - In this case, the student needs to understand the content covered in the question, define performance criteria, and think about prerequisites. They also learn to write clearly and develop self-assessment skills. Questions created by students can be multiple choice, free answers, and programming questions;

- Answer questions created by students - Student-generated tasks can be used by other students to practice their skills and review course material;

- Evaluate questions and answers - Students can provide feedback about the quality of the work of others;

- Discuss and provide feedback - Students can write comments, asking for clarification and providing ideas to improve the quality of others' content.

\section{Related Works}

Previous studies aimed to evaluate the correlation between the development of CSP-based activities and the behavioral and cognitive engagement of students. Students guided to create new programming activities and to solve questions generated by others can have higher outcomes in exams [Luxton-Reilly and Denny 2010, Falkner and Falkner 2012].

These studies also demonstrate that applying contribution pedagogy can be beneficial because the students develop skills while generating and evaluating material, and they can perform a self-assessment of content knowledge [Hamer et al. 2012]. Another benefit is the development of interpersonal skills [Gol and Nafalski 2007]. 
There are a few studies concerning the emotional dimension [Luxton-Reilly et al. 2018]. Martins emphasizes the importance of exploring emotional engagement in the task of programming the robot [Martin 2017]. Scaico shows what happened to the interest and motivation of beginners during an introductory experience [Scaico 2018]. It highlights the need to amplify the discussions around introductory programming education covering non-technical competencies, like students' interest, which seems crucial to how beginners learn to code.

The previous studies emphasize only one student engagement dimension, unlike the present study, that considered all three.

\section{Materials and Method}

This study aimed to investigate the effects on the engagement of students who perform CSP-based activities. An experimental study was conducted to evaluate the impact on students' dimensions of engagement who develop new programming activities.

Therefore, a research question was defined as $\mathbf{R Q : ~ W h a t ~ a r e ~ t h e ~ e f f e c t s ~ o n ~ t h e ~}$ engagement dimensions of those who develop new programming activities?

From this RQ, we define three other research questions to investigate how the dimensions are affected.

- RQ1: What are the effects on the behavioral engagement of those who develop new programming activities?

- RQ2: What are the effects on the cognitive engagement of those who develop new programming activities?

- RQ3: What are the effects on the emotional engagement of those who develop new programming activities?

We defined indicators to measure each dimension of student engagement, that are presented in Table 1 to measure the student engagement of subjects. Regarding to behavioral engagement, we used the number of new programming questions, average submission pace, and production session duration. The submission pace represents the time between each submission and production session is the time interval between the first and last submission. We used the degree of difficulty of the question to represent the cognitive effort to produce the content. So, the more difficult an exercise is, the longer the student is regarded as cognitively engaged. We measured the emotional engagement as the intensity of affective states' experience in developing new activities.

Table 1. Indicators of Student Engagement

\begin{tabular}{|c|c|}
\hline Student Engagement & \multicolumn{1}{c|}{ Indicator } \\
\hline Behavior & $\begin{array}{l}\text { Number of exercises, } \\
\text { Submission pace, } \\
\text { Session duration }\end{array}$ \\
\hline Cognitive & Degree of difficulty \\
\hline Emotion & Intensity of affective states \\
\hline
\end{tabular}

Subjects were randomly grouped into two groups: experimental and group. All participants were instructed to produce new programming activities. However, we only 
explicitly mentioned to the experimental group that the questions they would create would be used as part of their programming course's instructional material.

Based on this information, the study investigates the following null hypothesis:

- $H_{0}^{1}$ : The average number of questions produced by the experimental group is higher than that by the control group.

- $H_{0}^{2}$ : The average submission pace of the experimental group is higher than that of the control group.

- $H_{0}^{3}$ : The average duration of an exercise production session of the experimental group is higher than that of the control group.

- $H_{0}^{4}$ : The number of easy questions of the experimental group is greater than that of the control group.

- $H_{0}^{5}$ : The number of hard questions of the experimental group is lower than that of the control group.

- $H_{0}^{6}$ : The intensity of the affective states experienced by the experimental group participants is equal to that of the control group.

We invited students enrolled in the 2018.2 semester of an introductory programming course from the Federal University of Campina Grande to attend the experimental study. Instructors blended self-paced and mastery learning methods as strategies to teach the topics. Self-paced learning allows students to take the time they need to learn. Mastery learning strategy advocates that students need to master the content to achieve a higher degree of knowledge. The lecturers also distributed the course content into a sequence of smaller learning units.

To advance to the next unit, learners have to demonstrate mastery standards in the unit assessment.

So, the content program and how the units were defined is presented as follows:

- Units 1 and 2 include basic programming elements;

- Units 3, 4, and 5 address conditional statements and loops;

- Unit 6 address functions;

- Units 7, 8, 9 and 10 include data structures.

This grouping was balanced, considering the content unit students were exposed when the experiment took place. So, both groups were similarly related to the average unit. We guided all participants to create new programming exercises and submit them through Google Forms ${ }^{1}$, within a 1-hour session. Students in both groups were given a 1-hour session to create and submit new programming exercises. There were no lower or upper limits for the number of exercises. After this period of time, they answered a post-test questionnaire about the intensity of the affective states they experienced while developing the activities. The intensity was represented by a five-level Likert scale containing the options: not at all, a little, moderately, very much, and extremely.

\section{Results and Discussion}

Twenty-seven students accepted the invitation to attend the study. They were on average 19.5 years old, $89.7 \%$ were male, and the average of the unit was 6 . Control group had

\footnotetext{
${ }^{1}$ Retrieved from http://https://drive.google.com/ (2020, July 20)
} 
13 participants, while the experimental had 14. The average of the current unit is 6.38 of control and 6.5 of the experimental group.

RQ1: What are the effects on the behavioral engagement of those who develop new programming activities?

We use the single-tailed $t$-test to compare if there is a significant difference between the groups regarding the average of behavior engagement indicators: number of exercises $\left(H_{0}^{1}\right)$, submission pace $\left(H_{0}^{2}\right)$, and session duration $\left(H_{0}^{3}\right)$. With p-value resulting in $0.8023,0.4495$ and 0.9195 , respectively, we can't reject $H_{0}^{1}, H_{0}^{2}$, nor $H_{0}^{3}$. In doing so, we can answer the first research question and claim that developing new programming assignments may not influence behavioral engagement.

RQ2: What are the effects on the cognitive engagement of those who develop new programming activities?

To answer Research Question number 2, we used the difficulty of the exercises produced by the students to represent the effort applied by them in the creation process. We considered the more complicated to solve an activity is, the greater the cognitive effort spent by the author to create it. Thus, all participants in both groups were oriented to grade their own exercises as easy, reasonable, or hard.

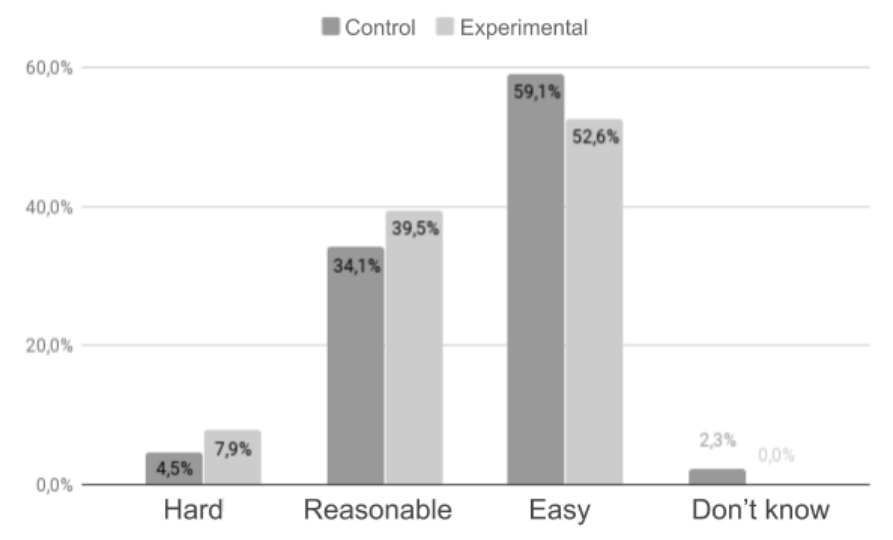

Figure 1. Degree of difficulty of produced programming exercises

Figure 1 presents how questions were classified by their authors according to the degree of difficulty. Participants in the control group produced 7\% more "easier" questions than that of the experimental group. Almost 39\% of items were considered "reasonable" for the experimental group, and $34 \%$ for the control group. About $7.9 \%$ of the experimental group questions were classified as "hard", while in the control group, $4.5 \%$ were. And $2.3 \%$ of subjects didn't know how to classify the degree of difficulty.

We reject $H_{0}^{4}$ and $H_{0}^{5}$ because the experimental group produced fewer "easy" questions and more "hard" than the control group. From the results, there is an indication that the development of new programming activities can affect cognitive engagement.

RQ3: What are the effects on the emotional engagement of those who develop new programming activities?

To answer RQ3, we asked participants about how they felt while creating the pro- 
gramming exercises, regarding the intensity of the following affective states: interested, motivated, useful, engaged, annoyed, stimulated, included, relevant, influential, productive, powerful, satisfied, proud, happy, astonished, ashamed, careful.

The following figures represent the reported intensity of the participants feelings, organized in labeled rectangular boxes. On the right-hand side of each box, we have the percentage of subjects who reported that the intensity of feeling was "very much" or "extremely", while on the left-hand side, we have the percentage who reported the intensity of feeling as "not at all" or "a little". And in the centre, the rate that reported feeling a state of "moderate" intensity.

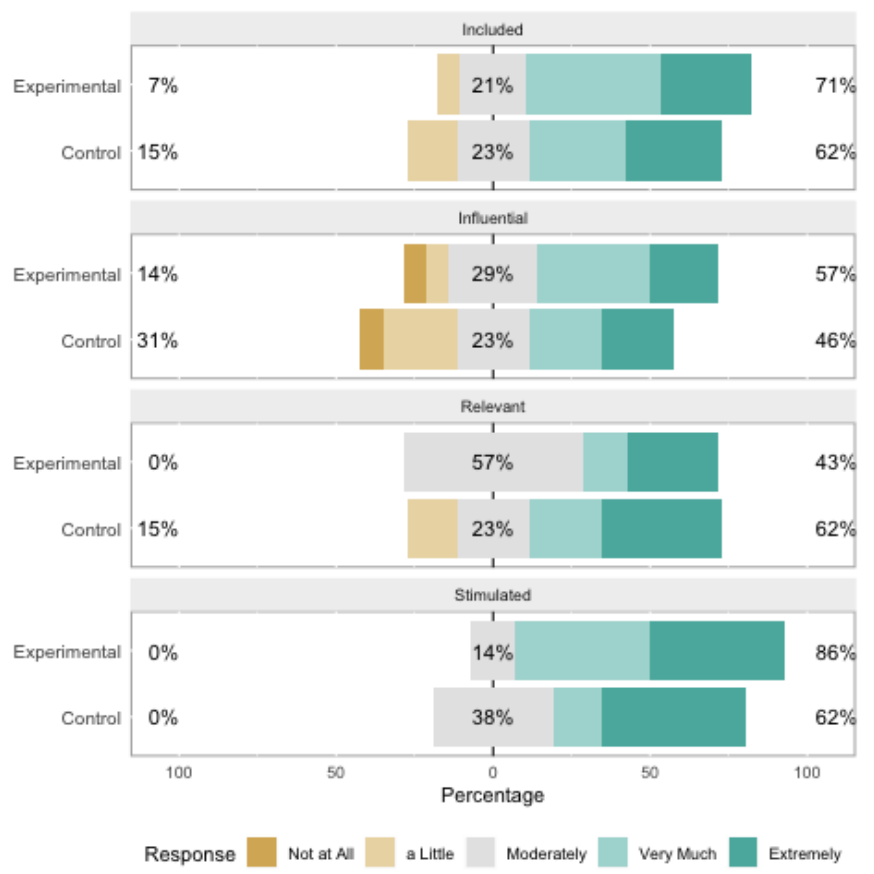

Figure 2. How Students Reported How They Felt While Performing the Activity (I)

Figure 2 reveals that participants of the experimental group felt more "included", "influential" and "stimulated" than those of the control group, since "very much" and "extremely" were more prevalent responses (71\% vs $62 \%, 57 \%$ vs $46 \%$ and $86 \%$ vs $62 \%$, respectively). On the other hand, they felt less "relevant" than those of the control group (43\% vs $62 \%)$.

Figure 3 presents that participants of the experimental group felt more "productive" and "satisfied" but less "powerful" and "proud" than those of the control group. The percentage of "very much" and "extremely" for "productive" affective state were remarkably high: $93 \%$ vs $69 \%$.

Figure 4 indicates that overall the participants of both group did not feel "ashamed/shy", because "not at all" and "a little" was reported by $71 \%$ and $54 \%$ of the experimental and control group participants, respectively. However, in control group, participants felt more "ashamed/shy" than those of the experimental group, because the formers reported $38 \%$ of "moderate" and $8 \%$ of "extremely" intensities, compared to $21 \%$ and $7 \%$ reported by the latters. Regarding the other affective states, control group par- 
IX Congresso Brasileiro de Informática na Educação (CBIE 2020)

Anais do XXXI Simpósio Brasileiro de Informática na Educação (SBIE 2020)

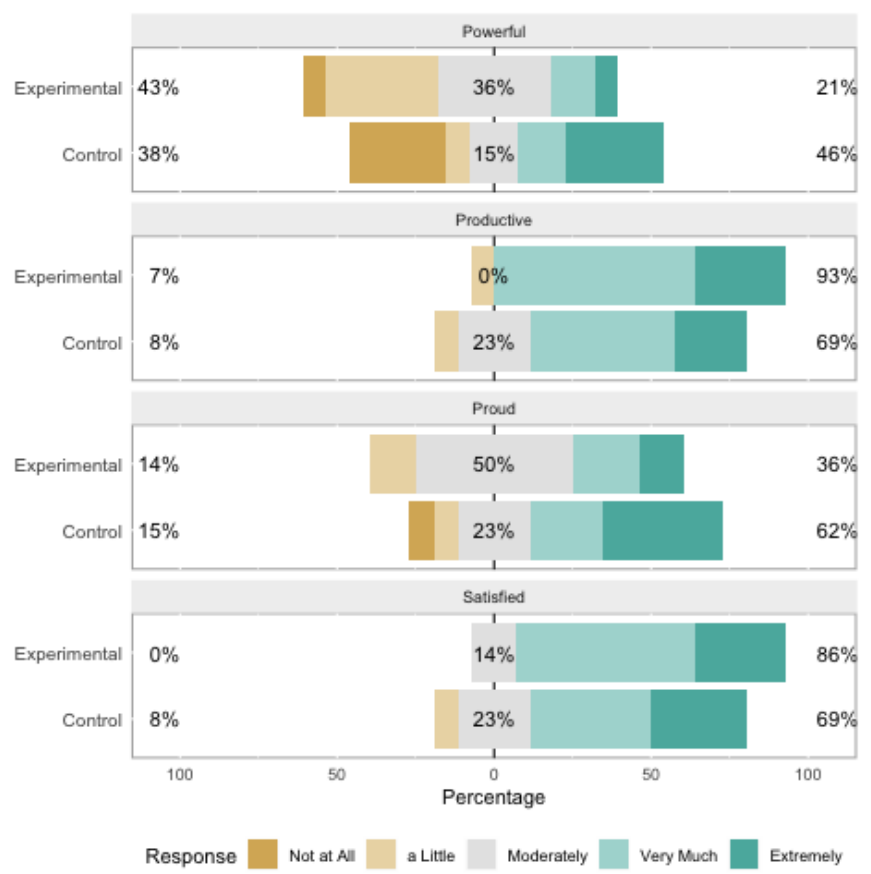

Figure 3. How Students Reported How They Felt While Performing the Activity (II)

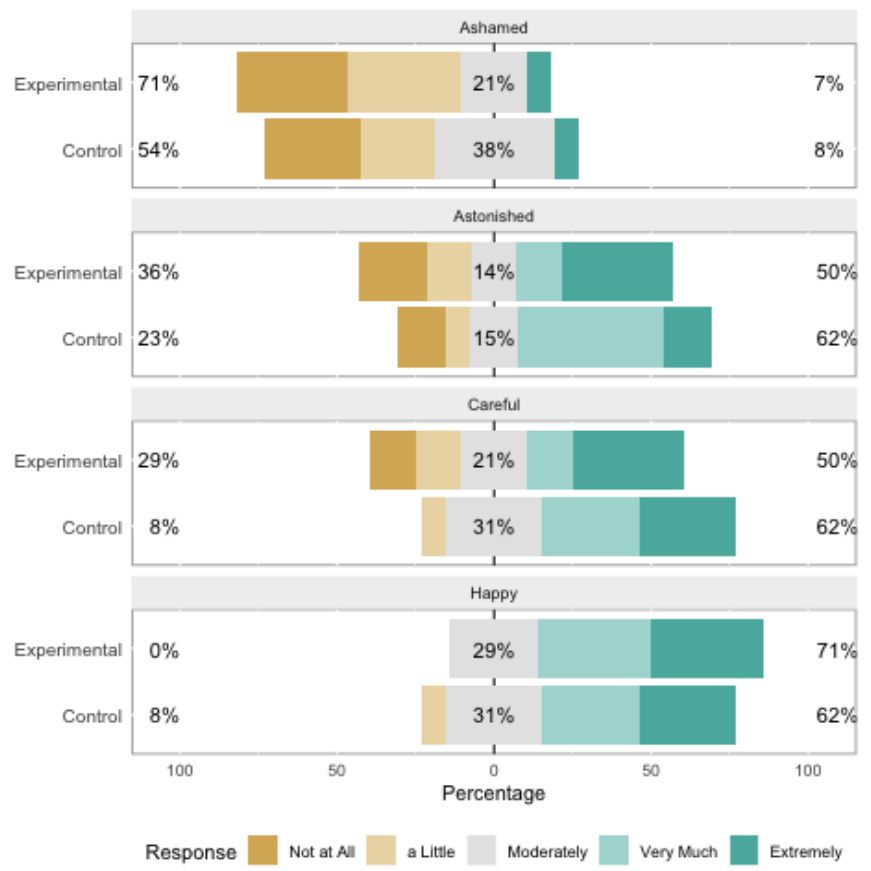

Figure 4. How Students Reported How They Felt While Performing the Activity (III)

ticipants were more "astonished" and "careful" (62\% each) and the experimental group participants were more "happy" (71\% of "very much" and "extremely" answers).

From these results, we cannot reject $H_{0}^{6}$ because there is an indication that the de- 
IX Congresso Brasileiro de Informática na Educação (CBIE 2020)

Anais do XXXI Simpósio Brasileiro de Informática na Educação (SBIE 2020)

velopment of new programming exercises can influence some affective states of emotional engagement.

All these findings provide evidence that creating new exercises can affect cognitive and emotional dimensions, but it cannot influence behavior engagement of students.

\section{Limitations}

The limitations of the present study include the low number of participants in our experiment, that might not represent all novice programmers. For this reason, conclusions may not be generalized to all introductory programming students, and more research using controlled trials is needed.

Another concern arises from the challenge of accurately classify questions. Because they are novices, participants may not know enough about the difficulties of the exercises to correctly evaluate them after their production.

Regarding the limitations of instruments and indicators used in the experiment, it could be necessary to investigate other tools and choose more representative metrics. Therefore further works could expand the understanding of students engagement.

\section{Conclusion}

In this research, we investigated if the activity of creating programming exercises, in an introductory programming course, could affect students engagement. We conducted an experimental study $(\mathrm{n}=27)$, where students were guided to create new questions.

Results indicate that developing new programming exercises do not influence students behavioural engagement. Cognitive engagement, however, was affected since more complex questions were created by the experimental group participants. The proposed activity can also influence students emotional engagement, once several affective states were intensified, such as "included", "influential", "stimulated", "productive", "satisfied" and "happy".

Results provide evidence that creating new programming exercises does not improve how "relevant", "powerful", "proud" and "careful" the student felt. We believe this outcome is due to the responsibility in producing content that will effectively be used in a course syllabus.

Despite limitations, these results provide instructors with an alternative teaching activity to improve student engagement. Moreover, students can improve their programming studies with a stimulating and productive learning strategy.

Analyzing students feedback about their experience in creating new programming questions should also be investigated, to better understand their perspectives performing new learning activities.

Future research could explore other indicators of student engagement to validate the findings identified in this study.

\section{References}

Collis, B. and Moonen, J. (2006). The contributing student: Learners as co-developers of learning resources for reuse in web environments. In Engaged learning with emerging technologies, pages 49-67. Springer. 
IX Congresso Brasileiro de Informática na Educação (CBIE 2020)

Anais do XXXI Simpósio Brasileiro de Informática na Educação (SBIE 2020)

Eltegani, N. and Butgereit, L. (2015). Attributes of students engagement in fundamental programming learning. In Computing, Control, Networking, Electronics and Embedded Systems Engineering (ICCNEEE), 2015 International Conference on, pages 101-106. IEEE.

Falkner, K. and Falkner, N. J. (2012). Supporting and structuring "contributing student pedagogy" in computer science curricula. Computer Science Education, 22(4):413443.

Fredricks, J. A., Blumenfeld, P. C., and Paris, A. H. (2004). School engagement: Potential of the concept, state of the evidence. Review of Educational Research, 74(1):59-109.

Gol, O. and Nafalski, A. (2007). Collaborative learning in engineering education. PhD thesis, Unesco, Internationa Centre for Engineering Education.

Hamer, J., Sheard, J., Purchase, H., and Luxton-Reilly, A. (2012). Contributing student pedagogy. Computer Science Education, 22(4):315-318.

Kay, A. E. (2016). Student-generated content: investigating student use of PeerWise. PhD thesis, The University of Edinburgh.

Konopka, C. L., Adaime, M. B., Mosele, P. H., et al. (2015). Active teaching and learning methodologies: some considerations. Creative Education, 6(14):1536.

Lee, J.-S. (2012). The effects of the teacher-student relationship and academic press on student engagement and academic performance. International Journal of Educational Research, 53:330-340.

Lester, D. (2013). A review of the student engagement literature. FOCUS on Colleges, Universities \& Schools, 7(1).

Luxton-Reilly, A., Albluwi, I., Becker, B. A., Giannakos, M., Kumar, A. N., Ott, L., Paterson, J., Scott, M. J., Sheard, J., Szabo, C., et al. (2018). Introductory programming: a systematic literature review. ITiCSE' 18, pages 55-106. ACM.

Luxton-Reilly, A. and Denny, P. (2010). Constructive evaluation: a pedagogy of studentcontributed assessment. Computer Science Education, 20(2):145-167.

Maia, M. C., de Figueiredo, J. C. A., and Serey, D. (2019). Online student engagement: A case study in teaching of programming. In Brazilian Symposium on Computers in Education (Simpósio Brasileiro de Informática na Educação-SBIE), page 51.

Martin, C. J. (2017). Designing Engaging Learning Experiences in Programming. PhD thesis, University of Dundee.

Pears, A. N. (2010). Enhancing student engagement in an introductory programming course. In 2010 IEEE Frontiers in Education Conference (FIE), pages F1E-1. IEEE.

Scaico, P. D. (2018). Um Estudo Sobre o Desenvolvimento de Interesse Pela Aprendizagem de Programação. $\mathrm{PhD}$ thesis, Universidade Federal de Pernambuco.

Sesmiyanti, S. (2016). Student's cognitive engagement in learning process. Journal Polingua: Scientific Journal of Linguistics, Literature and Education, 5(2):48-51.

Sinatra, G. M., Heddy, B. C., and Lombardi, D. (2015). The challenges of defining and measuring student engagement in science. Educational Psychologist, 50(1):1-13. 